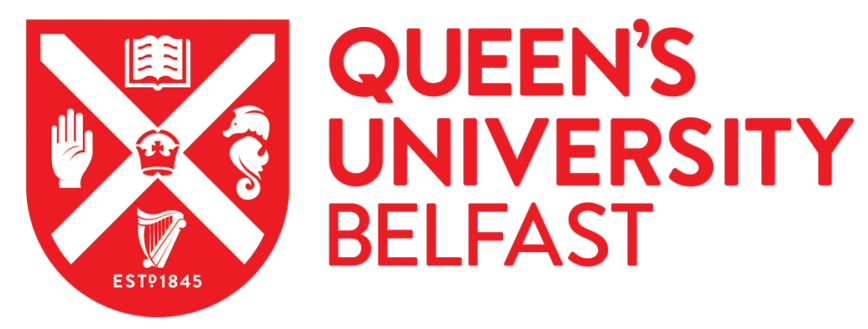

\title{
Teenage motherhood: where you live is also important. A prospective cohort study of 14,000 women
}

Wright, D. M., Rosato, M., Doherty, R., \& O'Reilly, D. (2016). Teenage motherhood: where you live is also important. A prospective cohort study of 14,000 women. Health and Place, 42, 79-86.

https://doi.org/10.1016/j.healthplace.2016.09.007

Published in:

Health and Place

Document Version:

Peer reviewed version

Queen's University Belfast - Research Portal:

Link to publication record in Queen's University Belfast Research Portal

Publisher rights

Copyright $\odot 2016$ Elsevier B.V. This manuscript version is made available under the CC-BY-NC-ND 4.0 license

$\mathrm{http}: / /$ creativecommons.org/licenses/by-nc-nd/4.0/ which permits distribution and reproduction for non-commercial purposes, provided the author and source are cited.

\section{General rights}

Copyright for the publications made accessible via the Queen's University Belfast Research Portal is retained by the author(s) and / or other copyright owners and it is a condition of accessing these publications that users recognise and abide by the legal requirements associated with these rights.

Take down policy

The Research Portal is Queen's institutional repository that provides access to Queen's research output. Every effort has been made to ensure that content in the Research Portal does not infringe any person's rights, or applicable UK laws. If you discover content in the Research Portal that you believe breaches copyright or violates any law, please contact openaccess@qub.ac.uk. 


\section{Teenage motherhood: where you live is also important. A}

2 prospective cohort study of 14,000 women

3 David M Wright ${ }^{1}$, Michael Rosato ${ }^{2}$, Rachel Doherty ${ }^{3}$, Dermot O'Reilly $^{1}$

4 1. Centre for Public Health, Queen's University Belfast, Belfast, UK

5 2. Bamford Centre for Mental Health and Wellbeing, Ulster University, Londonderry, UK

6 3. Public Health Agency, 12-22 Linenhall Street, Belfast, UK

7 Corresponding author: David M Wright

$8+442890978939$

$9 \quad$ d.wright@qub.ac.uk

10 Centre for Public Health, Institute of Clinical Sciences - Block B, Queen's University Belfast, Royal

11 Victoria Hospital, Grosvenor Road, Belfast, BT12 6BA, UK

13 Published: Health and Place (2016)

14 doi: http://dx.doi.org/10.1016/j.healthplace.2016.09.007 


\title{
16 Teenage motherhood: where you live is also important. A
}

17 prospective cohort study of 14,000 women

\author{
18 Abstract \\ 19 The United Kingdom has among the highest rates of teenage motherhood (TM) in Western Europe. \\ 20 The relationship to individual social and material disadvantage is well established but the influence \\ 21 of area of residence is unclear. We tested for additional TM risks in deprived areas or in cities. The \\ 22 Northern Ireland Longitudinal Study was used to identify 14,055 nulliparous females (15-18). TM risk \\ 23 was measured using multilevel logistic regression, adjusting for health status, religion, family \\ 24 structure, socio-economic status, rurality and employment-based area deprivation. Most variation in \\ 25 TM was driven by individual, household and socioeconomic factors with the greatest proportion of \\ 26 mothers in low value or social rented accommodation. Living in an area with fewer employment \\ 27 opportunities was associated with elevated TM risk (most vs. least deprived, $\mathrm{OR}_{\mathrm{adj}}=1.98$ [1.49, \\ 28 2.63]), as was urban dwelling (urban vs. intermediate, $\mathrm{OR}_{\mathrm{adj}}=1.42[1.13,1.78]$ ). We conclude that \\ area of residence is a significant independent risk factor for TM. Interventions should be targeted \\ towards the most deprived and urban areas and to those in the lowest value housing.
}

\section{Keywords}

32 teenage motherhood; urban/rural; area deprivation 


\section{Introduction}

36 Early child-bearing may have a profound impact on the well-being of adolescents, being associated with reduced educational attainment and curtailed career prospects (Chevalier et al., 2003; Navarro and Walker, 2012). Births to young teens (13 - 16 years old) have been associated with negative health outcomes for both mothers and children (Reime et al., 2008; Kuo et al., 2010) and children of teenage mothers are at increased risk of emotional and behavioural problems (Moffitt and the ERisk Study Team, 2002). Social and economic costs associated with supporting these groups may be considerable although there remains debate over whether teenage motherhood should be considered a social problem and whether early reproduction should be discouraged (Duncan, 2007; Bonell, 2004; Lawlor and Shaw, 2002).

The evidence base about individual and household factors associated with teenage motherhood is well established but the influence of area of residence is less clear. At the individual level, low socioeconomic status (SES), poor educational attainment and mental health problems have been associated with increased teenage motherhood risk (Kiernan, 1997; Lehti et al., 2012; Horwitz et al., 1991). Women born to young mothers may be more likely to become young mothers themselves (Kahn and Anderson, 1992; Lehti et al., 2012; Horwitz et al., 1991), as are those not living with both parents (Lehti et al., 2012). There have been fewer studies of teenage fatherhood but similar associations with low SES and educational attainment have been found (Kiernan, 1997). Associations between teenage fatherhood and problems at home and school, drug use and early onset of sexual activity have been reported (Dearden et al., 1995; Thornberry et al., 1997) but for teenagers of both sexes, birth of a child can mark a turning point towards more positive behaviours and maturity (Duncan, 2007; Enderstein and Boonzaier, 2015).

Many risk factors for teenage motherhood are shared with teenage pregnancy (Woodward et al., 2001; Imamura et al., 2007; Gibb et al., 2012), however some factors influence only post-conception reproductive decisions and so the strength of the relationship between teenage pregnancy and motherhood rates can vary considerably among populations (Smith, 1993). For example, variation in 
pregnancy outcomes among areas in England may be due to varying policies on abortion provision among health authorities (Diamond et al., 1999).

Ecological studies have revealed higher rates of teenage pregnancy in deprived areas (McLeod, 2001; Bradshaw et al., 2005) and risk increasing with distance to family planning clinics in some urban areas (Diamond et al., 1999). Family planning services may influence teenage pregnancy and motherhood rates at the area level; GP practices with female or younger doctors have been associated with lower teenage pregnancy rates (Hippisley-Cox et al., 1999). However, ecological studies cannot distinguish whether variation in risk is due to population composition (the characteristics of residents) or to features of the areas themselves. Rare multilevel studies have found residual regional variation in teenage pregnancy risk after adjusting for household SES and family structure (Finland) (Vikat et al., 2002) and elevated risks of teenage motherhood in some urban areas whilst adjusting for area deprivation, individual and household factors (UK) (McCulloch, 2001).

In this study, we develop a detailed picture of the risk factors for teenage motherhood, formally testing whether area level deprivation and urban/rural residence are associated with teenage motherhood risk independent of a wide range of individual and household characteristics. Rather than relying on survey responses from a potentially difficult to reach demographic group, we used a large scale linkage of birth records with Census records to investigate gradients of teenage motherhood risk in Northern Ireland (NI).

The social context surrounding teenage sexual behaviour and fertility differs between Northern Ireland and Great Britain. In Northern Ireland, abortion is illegal unless it can be proven that the life of the mother is at serious risk and so teenagers may travel to Great Britain to obtain an abortion. In 2014, $107 \mathrm{NI}$ resident women under twenty obtained an abortion in England or Wales (Department of Health, 2015). The number of $\mathrm{NI}$ residents obtaining an abortion in Scotland is not reported in 
official statistics as these women are frequently assigned a temporary postcode in Scotland for the purposes of treatment (Information Services Division, 2016).

Although some denominations are in decline, religious affiliation is an important indicator of social identity and churches retain a stronger influence on social norms especially regarding sexual behaviour than would be observed in Great Britain. There are separate school systems corresponding to the two dominant communities, the Catholic system and the state system that is predominantly attended by Protestants. Catholic schools have traditionally placed a low emphasis on contraception in the sex education curriculum (Rolston et al., 2005), consistent with the strong anti-abortion teaching of the Catholic Church. Opposition to abortion from both the Catholic Church and conservative Protestant denominations is largely responsible for the continued ban on abortion in NI.

To account for these features and to gain additional insight into underlying mechanisms we included measures not previously used in studies of teenage motherhood. Current religious affiliation was included as those with no religious affiliation might have lower risk of teenage motherhood due to increased use of contraception and/or use of abortion services compared with those declaring an affiliation. In addition to measures of SES based on parental occupation which reflect current exposure to social environments, we used house value as a measure of accumulated household wealth and indicator of cumulative exposure to these environments. Wealth may indirectly reduce teenage motherhood risk by encouraging teenagers to delay childbearing to pursue education and careers but may also have a direct influence by increasing the ability to travel to Great Britain to obtain an abortion.

Rates of teenage motherhood have decreased in the UK over recent years, a trend that partially reflects an increase in the proportion of pregnancies aborted; in England and Wales the proportion of pregnancies aborted among the under 20s increased from $34.7 \%$ in 1994 to $44.6 \%$ in 2014 (ONS, 2016). Despite this decreasing trend the UK has some of the highest rates of teenage motherhood in 
Western Europe. In 2012, there were 19.7 births per 1000 women aged 15-19 (ONS, 2014). In

\section{Methods}

\section{Data sources}

114 The study cohort was drawn from the Northern Ireland Longitudinal Study (NILS) which comprises data from the Northern Ireland Health Card registration system linked to Census and vital events data from administrative sources (O'Reilly et al., 2012). The representative sample covers approximately $28 \%$ of the population, an unprecedentedly large population fraction for a study of teenage motherhood. A cohort of nulliparous women aged 15 to 18 at the 2001 Census was identified. The 15 to 19 age range is widely used for comparisons of teenage motherhood rates over time and between countries (e.g. ONS, 2014; Kiernan, 1997). A focus of this analysis was on the influence of household and family characteristics on teenage motherhood risk and the likelihood of a young woman leaving the family home increases considerably at University entry age. Therefore we excluded those aged 19 at baseline because for women that have left home household characteristics were not available. Also for this reason we excluded 88 women living in communal establishments. The majority (59) were in educational establishments (including halls of residence), 14 were in children's homes and the remaining 15 were in hostels, care homes, prison or psychiatric hospitals. We also excluded 184 cases with incomplete information, leaving a final cohort size of 14,055 . The risk period for each woman comprised the period in which she remained under 20 , giving a maximum follow up duration of five years. First births were the primary outcome and at this point women were excluded from the risk set so subsequent births did not contribute to our estimates. Contextual information on the cohort members, drawn from 2001 Census returns was anonymised, held in a secure environment by the Northern Ireland Statistics and Research Agency (NISRA) and made available to the research team for this study. The use of the NILS for research was approved by the Office for Research Ethics Committees Northern Ireland (ORECNI). 


\section{Individual measures}

Cohort attributes were selected based on those factors previously associated with variation in teenage motherhood risk or that might plausibly be so. Two measures of self-reported health status were included; general health (good/fair/not good) and whether the respondent had a long term health condition that limited normal activities of daily living. Current religion (Roman Catholic/Church of Ireland/Methodist/No religion or other religion/Other Christian/Presbyterian) was recorded. Only 30 cohort members reported belonging to 'other' religions and so these were grouped with those reporting no religion. Previous analyses have demonstrated that Other Christians are more conservative and the group has healthier behaviours and outcomes ( $O^{\prime}$ Reilly and Rosato, 2010). Whether the cohort member was living with parents was also recorded. Cohort members were grouped into those living with both parents and those who were not, as an exploratory analysis revealed no statistically significant difference in teenage motherhood risk for those living with just one parent and those living with neither parent.

\section{Household factors}

Socio-economic status of the household was captured using four variables. Social class of the head of household was based on the National Statistics Socio-Economic Classification (NS-SEC)(Rose and Pevalin, 2002) and was used along with their economic activity (employed/inactive/unemployed). The head of household was identified using a combination of variables. Lone parents were taken to be head of household. In couple families, the partner with the highest level of economic activity was head. If both had the same activity, the elder was selected or if both were the same age, the first entered on the Census form was selected. If household members were unrelated, or there was more than one family present, the same set of rules was used to select the head from among them. Access to cars (none/one/two or more) was used along with a composite measure of housing tenure (owner occupied/privately rented/social rented) and value (house value classified into five categories if owner occupied). 
161 A measure representing potential employment prospects for cohort members based on the proportion of the population involuntarily excluded from the workforce was derived from the Multiple Deprivation Measure (MDM) (NISRA, 2005a). It was calculated for 890 Census Super Output Areas (SOAs, 2000 people each), which were then classified into quintiles.

There is no universally agreed definition of what constitutes an 'urban' or 'rural' area but the official classification in Northern Ireland (NISRA, 2005b) is based on population size, density and access to services. Census Output Areas ( 300 people each) are grouped into eight settlement bands ranging in size from settlements of less than 1000 people to the Metropolitan Area of Belfast (c. 580,000 people). To ensure an adequate sample size in each group, we re-categorised the bands into three similarly sized groups; urban - comprising the largest two cities; intermediate - combining large, medium, and small towns and intermediate areas; and rural - comprising open country and settlements of less than 1000 people.

174 Teenage motherhood risk was estimated using logistic regression. A base model was fitted in which spatial variation in teenage motherhood risk was modelled with a random effect for SOA as the sole predictor. Unadjusted associations between explanatory factors and teenage motherhood were assessed by comparing the fit of the base model with models including the factor as the only other predictor using Akaike's Information Criterion (AIC) and Likelihood Ratio Tests. The model with the minimum AIC from the candidate set is the best fitting and a commonly used rule of thumb is that models with AICs four or more units greater than the minimum have substantially less support from the data (Burnham and Anderson, 2004). Adjusted estimates were obtained using multivariable models including combinations of factors associated with teenage motherhood in the univariable analysis. As the influences of individual and household factors on teenage motherhood risk may vary along urban/rural gradients, two-way interactions with settlement band were also tested (in an exploratory analysis a set of fixed effects models stratified by settlement band was fitted which 
indicated the most plausible interactions to test). As a sensitivity analysis, a fully-adjusted model excluding the car access variable was fitted to test whether its inclusion obscured any urban/rural effects, as car access is known to be greater in rural areas for given levels of deprivation.

We conducted a secondary analysis to assess the associations between intergenerational factors (cohort members' mothers' reproductive age and marital status) and risk of teenage motherhood, using the subset of cohort members living with their mothers for which this information was available. A model was fitted including these two factors in addition to those from the best fitting model identified in the primary analysis and estimates were compared between models (the living with both parents variable was excluded from the secondary analysis as this was confounded with mothers' marital status).

Models were fitted using the Ime4 package (Bates et al., 2014) within the $R$ software environment ( $\mathrm{R}$ Development Core Team, 2012). Logistic regression was used rather than time to event analysis as implementation of multilevel models was considerably less computationally intensive. Given the relatively short at risk period for each cohort member the two methods are likely to yield similar estimates of associations with teenage motherhood risk; this was confirmed in exploratory analysis by comparing estimates from the best fitting logistic model from the primary analysis with a (fixed effects only) Cox model containing the same factors (available on request).

\section{Results}

204 Of the 14,055 cohort members, $902(6.4 \%)$ became mothers during a total of 49,327 person years at risk, translating to an unadjusted rate of 18.3 births per 1000 person years at risk. Table 1 shows the baseline characteristics of those that became mothers and those that did not. A slightly smaller proportion of mothers had good general health than non-mothers but similar proportions in both groups reported long-term limiting illness. Cohort distribution by religious affiliations was similar across groups (Table 1) with the exception of those who classified themselves as 'other Christian' or 
211 were half as likely to identify as other Christians. Mothers were substantially less likely to live with

212 both parents or to be from households where the head of household was employed. Mothers were more likely to live in households where the head of household was in a lower status occupation, accommodation was rented (especially social housing) or the household had no car (Table 1). In total, $76 \%$ of teenage mothers lived in rented accommodation or housing within the lower two value categories, compared with $45 \%$ of non-mothers. Mothers were substantially more likely to live in urban or the most deprived areas than non-mothers ( $53 \%$ of mothers lived in urban areas, compared with $37 \%$ of non-mothers; Table 1). All factors were associated with teenage motherhood in unadjusted models and were included in the multivariable models with the exception of long-term limiting illness.

Table 2 shows estimated variation in teenage motherhood risk associated with individual and household level predictors from both unadjusted and the best-fitting adjusted model ( $\mathrm{A}$ - which also adjusted for area level predictors). For most factors, adjustment reduced the magnitude of associations with teenage motherhood risk. Following adjustment, cohort members who reported no religious affiliation were at $42 \%$ increased risk of teenage motherhood compared with Roman Catholics. There were no significant differences in risk between Catholics and those belonging to the major Protestant denominations (Table 2). There was an indication that those identifying themselves as 'other Christian' (primarily conservative Protestants) were at reduced risk relative to the mainstream groups although uncertainty around the estimate rendered the comparison statistically insignificant (Table 2).

\section{Household factors}

There was a strong relationship between teenage motherhood and household SES though this varied with the measure used. Unadjusted associations between teenage motherhood risk and economic activity or social class of the head of the household were attenuated following adjustment such that 
237 a professional occupation, in which case risk of teenage motherhood was lower than for the reference group (intermediate occupations). However, cohort members from households with two or more cars remained at $41 \%$ decreased risk of teenage motherhood compared with households with no cars.

House value and tenure, the novel measure of accumulated wealth, was associated with the largest

242 variation in teenage motherhood risk (adjusted OR range 0.25, 1.14 compared with 1.00, 1.98 for employment based area deprivation). There was a pronounced decrease in teenage motherhood risk with increasing house value; cohort members in households within the highest value category were at $75 \%$ less risk than those in the lowest value category. Those in rented accommodation were at similar risk to those in the lower two value categories. However, inclusion of house value did not substantially alter the relationships between teenage motherhood and other household measures of SES or individual level variables. With the exception of the effect for two or more cars, estimated effect sizes from the fully adjusted model all lay within the $95 \%$ Cls from a model in which only the conventional measures were included (Table 2 , right hand column). This indicates that house value represents a different dimension of SES to existing measures. There was additional variation in teenage motherhood risk associated with area of residence; inclusion of area level factors in adjusted models significantly improved model fit (decrease in AIC comparing model without area level factors, E with fully adjusted model, A, Table 3). There was a strong positive association between employment deprivation and teenage motherhood risk in the fully adjusted model (Table 4) and those in areas where the labour market was weakest were at $98 \%$ increased risk of teenage motherhood relative to those in the least deprived areas. evidence of an interaction between settlement band and family structure (better fit of model A including interaction term than model B without interaction, Table 3). The proportion of cohort 
members living with both parents decreased from rural to urban areas $(85 \%, 70 \%$ and $65 \%$ in rural, intermediate and urban areas respectively). For this group there was a gradient of increasing teenage motherhood risk from rural to urban areas in unadjusted models but evidence for an independent association following adjustment for other factors was weaker (Table 4, Figure 1). Those not living with both parents were at increased risk of teenage motherhood relative to those living with both parents in all areas (Figure 1) but the risk differential increased from urban to rural areas (ORs of 1.18, 1.34 and 2.16 in urban, intermediate and rural areas respectively). The highest teenage motherhood risks for those not living with both parents were in rural areas, followed by urban and then intermediate areas (Figure 1).

Sensitivity analysis indicated that inclusion of the car access variable did not obscure urban/rural effects. Similar gradients were obtained from models including and excluding the variable (Table 4). In the best-fitting model, the standard deviation of the area (SOA) level random effects was negligible $(<0.001)$ and so residual variation among SOAs contributes little to variation in teenage motherhood risk compared with other factors.

277 A total of 12,942 cohort members were living with their mothers of which $804(6.2 \%)$ became mothers themselves. The secondary analysis of this group indicated that mothers' age and marital status were strongly associated with teenage motherhood risk of members in both unadjusted and adjusted models (Table 5). Following adjustment, members whose mothers were young (aged $<20$ at birth of the cohort member) were more than twice as likely to become teenage mothers as those with older mothers (aged 30 or older). Members with mothers who were separated, divorced or remarried were all at greater risk of teenage motherhood than those with married mothers. There were no significant differences in risk between those with married mothers and those whose mothers were single or widowed. Estimated associations with other factors were of similar magnitude to those obtained from the primary analysis (all estimates from the secondary analysis 
were within the corresponding 95\% confidence intervals - not shown) indicating that these two factors made an independent contribution to risk of teenage motherhood.

\section{Discussion}

290 This study demonstrates that area of residence is independently associated with risk of teenage motherhood. This suggests that geographical variation in teenage pregnancy risk found in multiple European area-based studies (Imamura et al., 2007; Diamond et al., 1999; Bradshaw et al., 2005) cannot be attributed solely to the types of people living in these areas. The risk gradient associated with area-level employment deprivation was considerable, of greater magnitude than those associated with standard household-level measures of SES (e.g. car access).

Although this study did not set out to explore the ways in which area factors influence teenage motherhood, these findings offer some insights into potential underlying mechanisms. We recognise that the associations reported are a conflation of the three main stages leading to teenage motherhood (sexual activity, contraception and abortion). A possible mechanism by which area deprivation may incur additional teenage motherhood risk is through the establishment of early reproductive onset as a social norm (Arai, 2007). This may occur in response to poor labour market and career prospects, as under these conditions postponing family formation to invest time in education and career establishment may have little perceived value. However, the area measure of employment disadvantage was closely correlated with the equivalent measures of income and education deprivation and high teenage motherhood rates may reflect fertility decisions in reaction to shorter healthy life expectancies in deprived areas (Nettle, 2011). Social norms may also explain the lower levels of contraceptive usage found in the most deprived areas of Great Britain (Bentley et al., 2009), although the latter may instead be an indicator of more risky behaviour especially with relation to alcohol (Holmberg and Berg-Kelly, 2002). Our finding that cohort members with young mothers were more likely to become teenage mothers themselves is consistent with other studies

311 (Kahn and Anderson, 1992; Lehti et al., 2012; Horwitz et al., 1991) and so intergenerational 
repetition of fertility behaviours within families is a likely mechanism by which a norm could become established in an area.

314 Risk of teenage motherhood increased along the rural-urban gradient; more than half of teenage 315 mothers were from urban areas, despite the fact that only $38 \%$ of the cohort lived in these areas. 316 Consistent with studies of teenage pregnancy (Vikat et al., 2002; McLeod, 2001), this gradient was 317 attenuated following adjustment for household and employment-based area deprivation, highlighting the importance of considering factors operating at multiple scales. It is unlikely that urban/rural variation in teenage motherhood risk was due to distance to family planning services (see McLeod, 2001; Diamond et al., 1999; Bradshaw et al., 2005) as these are clustered in urban areas. Urban areas carried a considerably greater teenage motherhood risk than expected based on deprivation levels and it is possible that teenage motherhood is more closely associated with teenagers' perceptions of the residential environment and future prospects than measured deprivation (Johns, 2011), though the opportunities arising from the greater concentration of teenagers may also play a role. Negative perceptions of life prospects have been associated with other adolescent risk behaviours (e.g. substance use) in Northern Ireland (McKay et al., 2013) and may be more entrenched in deprived urban than rural areas, perhaps due to spatial aggregation of deprivation. Care should be taken before applying these findings to other populations. Studies in multiple countries have compared levels of adolescent risk behaviours along urban-rural gradients (Levine and Coupey, 2003; Forsyth and Barnard, 1999; Chan et al., 2016) but there is no general consensus as to whether those in urban areas adopt these behaviours at a younger age and 'grow up faster' than their rural counterparts. This is likely to be at least partially due to the lack of a universal definition of urban and rural areas; estimates of adolescent smoking and drinking risk in the same population have been shown to vary considerably depending on the definition chosen (Brady and Weitzman, 2007). 
Consistent with European studies (Vikat et al., 2002; Woodward et al., 2001), we found variation in

337

338

339

340

341

342

343

344

345

346

347

348

350

351

352

353

354

355

356

357

358

359

360

teenage motherhood risk at the household level but the greatest variation was associated with a novel measure of accumulated wealth (housing value and tenure). Those in low value accommodation were at substantially increased risk and $40 \%$ of teenage mothers were in social rented housing. At the operational level, wealth may facilitate the procurement of abortion but these findings again highlight that teenage motherhood as a norm may be most established in areas with the highest concentrations of social housing. This hypothesis might be investigated in future by fine-scale classification of areas based on proportion of social housing.

In contrast with other studies (e.g. Vikat et al., 2002), we found no graded association between socio-economic class of the head of household and teenage motherhood risk, although those from professional/managerial households were at lower risk in all models. This may indicate that property value as a measure of accumulated wealth better reflects cumulative exposure to social environments conducive to teenage motherhood than current household social position. Therefore we suggest that this measure should be used alongside occupation-based classifications of SES in risk factor studies to gauge the relative influence of past and present SES.

We found that religious affiliation was associated with reduced teenage motherhood risk, indicating that personal beliefs and social structures appear to maintain a regulatory influence on sexual behaviour among teenagers within the major Christian denominations. Contrary to expectation, there was no difference in teenage motherhood risk between Roman Catholics and mainstream Protestant groups despite differences in provision of sex education (Rolston et al., 2005; McLaughlin et al., 2007), suggesting that the previously more conservative, marriage focused curriculum in Catholic schools does not substantially reduce overall risk of teenage motherhood. Whilst Roman Catholics are less likely than Protestants to have sex before the age of 16 (Rolston et al., 2004; Schubotz et al., 2004), this may be offset by higher levels of sexual activity as older teens, along with similar levels of contraception use in both groups (McLaughlin et al., 2007). 
361 Our study had limitations. We were unable to investigate the influence of education on teenage motherhood because cohort members were at varying educational stages on Census day. Also, records were only available for births within Northern Ireland, excluding those who might have emigrated or travelled to Great Britain or the Republic of Ireland to give birth, potentially leading to underestimation of overall teenage motherhood risk. Any bias is likely to be small because the NI population has relatively low rates of migration (Shuttleworth et al., 2013) and there are few compelling reasons why residents should choose to travel to give birth. However, there may be variation among social groups in propensity to travel (especially to Great Britain) to obtain abortions, which are illegal in Ireland (both NI and the Republic, although there are specific exceptions when the mother's life is at serious risk). Both the costs and the concept of travel beyond the immediate locality are likely to act as significant barriers for those in the most deprived groups, potentially contributing towards the elevated teenage motherhood risks for those with low household wealth. A further drawback is that we were unable to determine at which of the stages (sexual behaviour and contraception; propensity for abortion) a factor has the greatest influence on teenage motherhood risk. Parallel analyses of risk factors for teenage pregnancy and teenage motherhood might further disentangle these mechanisms and it is hoped that birth and pregnancy records for this population will be available in future.

We used multilevel models to estimate the strength of associations between teenage motherhood and factors operating at the individual, household and area levels. Our study had limitations common to others in which Census tracts are used to measure area effects on health; tracts may not cohere with actual boundaries of neighbourhoods or communities and derived measures such as the MDM may not adequately represent underlying area factors that influence health (Riva et al., 2006). Care must be taken when interpreting multilevel models as they may not accurately represent the relative causal influences of each level (Diez-Roux, 2007). For instance, residence in a particular area for an extended time may alter the characteristics of its inhabitants and so variation associated with area may be underestimated (and individual level variation overestimated) using multilevel models. 
Conversely, inhabitants may be selected into areas based on individual characteristics that are also related to the outcome of interest (Diez Roux, 2004). In our study the greatest potential for overlap is between the household and area levels with households with only one parent or in social housing more likely to be selected towards the poorest areas. A related issue is that house values are likely to be influenced by area deprivation and so are intermediate on the hypothesised pathway from area deprivation to teenage motherhood risk. Inclusion of both factors within the same model may therefore have introduced a degree of statistical over-adjustment, with underestimation of the association between area deprivation and teenage motherhood risk the most likely outcome. The true magnitude of the association is likely to be intermediate between the unadjusted and fully adjusted (model A) estimates. The fact that we found strong area level effects despite these limitations (which are each likely to have diluted area effects) underlines the importance of area in explaining teenage motherhood. Despite these limitations, our estimate of the overall teenage motherhood rate (18.2 births per 1000 person years) was relatively close to official estimates for Northern Ireland, indicating that our cohort was broadly representative of the population, where fertility rates in the 15-19 age group declined during the study period from 23.9 in 2001 to 21.5 in 2005 (NISRA, 2015). Our lower estimate may be partially due to exclusion of second births and those living in communal institutions. The upper age limit for cohort members of 18 at Census is also likely to have reduced our estimate because 19 year olds are at the highest risk in the age range. Nonenumeration in the Census may have contributed to the lower estimate but the influence of response bias is likely to be minor compared with survey-based studies (approximately $95 \%$ of the population were enumerated).

In the largest individual-level study in the UK we have shown that risk of teenage motherhood varies with area of residence independently of a comprehensive range of individual and household characteristics. Those living in urban or more deprived areas were at increased risk of teenage motherhood but household factors (particularly wealth) were associated with the greatest variation in risk. Therefore, policies aiming to reduce teenage motherhood rates may be most effective if 
413 targeted at deprived areas, in which the majority of teenage mothers live, and towards those living

414 in rented or low value housing. As employment-based area deprivation and low value housing is 415 often concentrated in cities, efforts to reduce teenage motherhood rates in urban areas may bring 416 the greatest benefits.

\section{Acknowledgements}

418 The help provided by the staff of the Northern Ireland Longitudinal Study (NILS) and the NILS 419 Research Support Unit is acknowledged. The NILS is funded by the Health and Social Care Research 420 and Development Division of the Public Health Agency (HSC R\&D Division) and NISRA. The NILS-RSU 421 is funded by the ESRC and the Northern Ireland Government. The authors alone are responsible for 422 the interpretation of the data and any views or opinions presented are solely those of the authors 423 and do not necessarily represent those of NISRA/NILS. DMW and DOR were funded by the ESRC and 424 HSC R\&D division (grants ES/L007509/1 and STL/4918/13).

\section{References}

426 Arai, L., 2007. Peer and neighbourhood influences on teenage pregnancy and fertility: Qualitative 427 findings from research in English communities. Health \& place 13, 87-98.

Bates, D., Maechler, M., Bolker, B., Walker, S., 2014. Ime4: Linear mixed-effects models using Eigen and S4. Arxiv e-print, 1406.5823.

Bentley, R., Kavanagh, A., Smith, A., 2009. Area disadvantage, socioeconomic position and women's contraception use: a multilevel study in the UK. Journal of Family Planning and Reproductive Health Care 35, 221-226. quantitative research from the USA and UK. Culture, Health \& Sexuality 6, 255-272. 
Bradshaw, J., Finch, N., Miles, J.N.V., 2005. Deprivation and variations in teenage conceptions and abortions in England. Journal of Family Planning and Reproductive Health Care 31, 15-19.

437

Brady, J.E., Weitzman, B.C., 2007. Inconsistencies in place definition: How different operational place definitions affect estimates of adolescent smoking and drinking risk. Health \& place $13,562-568$.

Burnham, K.P., Anderson, D.R., 2004. Multimodel Inference: Understanding AIC and BIC in Model Selection. Sociological Methods \& Research 33, 261-304.

441 Chan, G.C.K., Leung, J., Quinn, C., Kelly, A.B., Connor, J.P., Weier, M., Hall, W.D., 2016. Rural and 442 Urban Differences in Adolescent Alcohol Use, Alcohol Supply, and Parental Drinking. The Journal of Rural Health 32, 280-286.

444 Chevalier, A., Viitanen, T.K., Viitanen, T.K., 2003. The long-run labour market consequences of 445 teenage motherhood in Britain. Journal of Population Economics 16, 323-343.

Dearden, K.A., Hale, C.B., Woolley, T., 1995. The antecedents of teen fatherhood: a retrospective case-control study of Great Britain youth. Am J Public Health 85, 551-554. 2014https://www.gov.uk/government/collections/abortion-statistics-for-england-and-wales. 273-289. a complex world. Social science \& medicine 58, 1953-1960. 
Diez-Roux, A., 2007. Neighborhoods and health: where are we and were do we go from here? Revue d'epidemiologie et de sante publique 55, 13-21.

457

Duncan, S., 2007. What's the problem with teenage parents? And what's the problem with policy?

458

Critical Social Policy 27, 307-334.

459

Enderstein, A.M., Boonzaier, F., 2015. Narratives of young South African fathers: redefining

460 masculinity through fatherhood. Journal of Gender Studies 24, 512-527.

Forsyth, A.J.M., Barnard, M., 1999. Contrasting levels of adolescent drug use between adjacent urban and rural communities in Scotland. Addiction 94, 1707-1718.

Gibb, S.J., Fergusson, D.M., Horwood, L.J., 2012. Childhood family income and life outcomes in adulthood: Findings from a 30-year longitudinal study in New Zealand. Social science \& medicine 74, 1979-1986.

Hippisley-Cox, J., Allen, J., Pringle, M., Ebdon, D., McPhearson, M., Churchill, D., Bradley, S., 1999. Association between teenage pregnancy rates and the age and sex of general practitioners: cross sectional survey in Trent 1994-7. BMJ : British Medical Journal 320, 842-845.

Holmberg, L., Berg-Kelly, K., 2002. Health, health-compromising behaviour, sexuality and involvement in pregnancy among 18-year-old Swedish males: a cross-sectional survey. Acta Pædiatrica 91, 838-843. parenthood. Family planning perspectives $23,168-177$. Jahn, A., Karro, H., Olsen, J., Temmerman, M., 2007. Factors associated with teenage pregnancy in 

the European Union countries: a systematic review. The European Journal of Public Health 17, 630636. 2015.http://www.isdscotland.org/Health-Topics/Sexual-Health/Abortions/.

Johns, S.E., 2011. Perceived environmental risk as a predictor of teenage motherhood in a British population. Health \& place 17, 122-131. 57.

Kiernan, K.E., 1997. Becoming a Young Parent: A Longitudinal Study of Associated Factors. The British journal of sociology $48,406-428$. pregnancies: Results of a Taiwanese national survey. Pediatrics International 52, 447-452. problem. International journal of epidemiology 31, 552-553.

Lehti, V., Niemelä, S., Heinze, M., Sillanmäki, L., Helenius, H., Piha, J., Kumpulainen, K., Tamminen, T., Almqvist, F., Sourander, A., 2012. Childhood predictors of becoming a teenage mother among Finnish girls. Acta Obstetricia et Gynecologica Scandinavica 91, 1319-1325. status: is "urban" a risk factor? Journal of Adolescent Health 32, 350-355. households. Journal of epidemiology and community health 55, 16-23. 
McKay, M.T., Percy, A., Cole, J.C., 2013. Present orientation, future orientation and alcohol use in

McLeod, A., 2001. Changing patterns of teenage pregnancy: population based study of small areas.

Moffitt, T.E., the E-Risk Study Team, 2002. Teen-aged mothers in contemporary Britain. Journal of proximate explanations. Philosophical Transactions of the Royal Society B: Biological Sciences 366, 357-365.

511 NISRA. 2015 Age-specific fertility rates, Northern Ireland 2001-2013 [online].

512 Available:http://www.nisra.gov.uk/demography/default.asp23.htm.

NISRA. 2005aNorthern Ireland Multiple Deprivation Measure 2005The Stationary OfficeNorwich, UK. and delineation of settlements.Northern Ireland Statistics and Research AgencyBelfast.

516 O'Reilly, D., Rosato, M., 2010. Dissonances in self-reported health and mortality across

517 denominational groups in Northern Ireland. Social science \& medicine 71, 1011-1017. 
518 O'Reilly, D., Rosato, M., Catney, G., Johnston, F., Brolly, M., 2012. Cohort description: The Northern

519 Ireland Longitudinal Study (NILS). International journal of epidemiology 41, 634-641.

520 ONS. 2016 Conceptions in England and Wales:2014 [online].

521 Available:http://www.ons.gov.uk/peoplepopulationandcommunity/birthsdeathsandmarriages/conc

522 eptionandfertilityrates/bulletins/conceptionstatistics/2014;.

523 ONS. 2014 International comparisons of teenage births [online].

524 Available:http://www.ons.gov.uk/ons/rel/vsob1/births-by-area-of-usual-residence-of-mother--

525 england-and-wales/2012/sty-international-comparisons-of-teenage-pregnancy.html.

526 R Development Core Team, 2012. R: A Language and Environment for Statistical Computing. R

527 Foundation for Statistical Computing, Vienna, Austria.

528 Reime, B., Schucking, B., Wenzlaff, P., 2008. Reproductive outcomes in adolescents who had a

529 previous birth or an induced abortion compared to adolescents' first pregnancies. BMC Pregnancy

530 and Childbirth 8, 4.

531 Riva, M., Gauvin, L., Barnett, T.A., 2006. Toward the next generation of research into small area

532 effects on health: a synthesis of multilevel investigations published since July 1998. Journal of

533 epidemiology and community health 61, 853-861.

534 Rolston, B., Schubotz, D., Simpson, A., 2004. The first time: young people and sex in Northern

535 Ireland. Journal of Youth Studies 7, 191-207.

536 Rolston, B., Schubotz, D., Simpson, A., 2005. Sex education in Northern Ireland schools: a critical

537 evaluation. Sex Education 5, 217-234.

538 Rose, D., Pevalin, D., 2002. A Researcher's Guide to the National Statistics Socio- Economic

539 Classification. Sage, London. 
540 Schubotz, D., Rolston, B., Simpson, A., 2004. Sexual behaviour of young people in Northern Ireland:

541 first sexual experience. Critical Public Health 14, 177-190.

542 Shuttleworth, I., Barr, P.J., Gould, M., 2013. Does Internal Migration in Northern Ireland Increase

543 Religious and Social Segregation? Perspectives from the Northern Ireland Longitudinal Study (NILS)

544 2001-2007. Population, Space and Place 19, 72-86.

545 Smith, T., 1993. Influence of socioeconomic factors on attaining targets for reducing teenage

546 pregnancies. BMJ : British Medical Journal 306, 1232-1235.

547 Thornberry, T.P., Smith, C.A., Howard, G.J., 1997. Risk Factors for Teenage Fatherhood. Journal of 548 Marriage and Family 59, 505-522.

549 Vikat, A., Rimpelä, A., Kosunen, E., Rimpelä, M., 2002. Sociodemographic differences in the 550 occurrence of teenage pregnancies in Finland in 1987-1998: a follow up study. Journal of 551 epidemiology and community health 56, 659-668.

552 Woodward, L., Fergusson, D.M., Horwood, L.J., 2001. Risk Factors and Life Processes Associated with 553 Teenage Pregnancy: Results of a Prospective Study From Birth to 20 Years. Journal of Marriage and 554 Family 63, 1170-1184. 
557 Table 1. Baseline characteristics of 15-18 year old nulliparous females in Northern Ireland, 2001 by teenage 558 motherhood status.

\begin{tabular}{|c|c|c|}
\hline & Non-mothers (\%) & Teenage mothers (\%) \\
\hline Cohort (N) & 13153 & 902 \\
\hline \multicolumn{3}{|l|}{ Individual } \\
\hline \multicolumn{3}{|l|}{ General health } \\
\hline Good & 89.2 & 85.0 \\
\hline Fair & 9.0 & 13.0 \\
\hline Not good & 1.8 & 2.0 \\
\hline \multicolumn{3}{|l|}{ Long term limiting illness } \\
\hline Yes & 5.1 & 6.2 \\
\hline No & 94.9 & 93.8 \\
\hline \multicolumn{3}{|l|}{ Religion } \\
\hline Roman Catholic & 47.5 & 49.9 \\
\hline Church of Ireland & 13.2 & 13.9 \\
\hline Methodist & 3.2 & 3.3 \\
\hline No religion & 11.2 & 15.6 \\
\hline Other Christian & 5.8 & 2.7 \\
\hline Presbyterian & 19.0 & 14.6 \\
\hline \multicolumn{3}{|l|}{ Living with both parents } \\
\hline Yes & 74.1 & 50.4 \\
\hline No & 25.9 & 49.6 \\
\hline \multicolumn{3}{|l|}{ (Head of) household } \\
\hline \multicolumn{3}{|l|}{ Economic activity } \\
\hline Employed & 76.7 & 55.3 \\
\hline Unemployed & 3.8 & 7.8 \\
\hline Inactive/Student & 19.5 & 36.9 \\
\hline \multicolumn{3}{|l|}{ Social class (NS-SEC) } \\
\hline Professional/Managerial & 28.9 & 14.7 \\
\hline Intermediate/Small employers/Self employed & 25.0 & 18.4 \\
\hline Lower supervisory/routine & 39.5 & 51.9 \\
\hline Long term unemployed/full-time student & 6.5 & 15.0 \\
\hline \multicolumn{3}{|l|}{ Housing tenure } \\
\hline Owner occupied: more than $£ 200,000$ & 11.8 & 2.1 \\
\hline Owner occupied: $£ 150,000-£ 199,999$ & 14.1 & 5.4 \\
\hline Owner occupied: $£ 100,000-£ 149,999$ & 23.3 & 14.1 \\
\hline Owner occupied: $£ 75,000-£ 99,999$ & 13.2 & 14.5 \\
\hline Owner occupied: less than $f 75,000$ & 9.2 & 12.3 \\
\hline Owner occupied: value unknown & 5.6 & 2.3 \\
\hline Privately rented & 5.0 & 8.9 \\
\hline Social rented & 17.8 & 40.4 \\
\hline \multicolumn{3}{|l|}{ Car access } \\
\hline None & 14.3 & 36.8 \\
\hline One & 39.5 & 43.1 \\
\hline Two+ & 46.1 & 20.1 \\
\hline \multicolumn{3}{|l|}{ Area } \\
\hline \multicolumn{3}{|l|}{ Settlement band } \\
\hline Rural & 30.3 & 15.7 \\
\hline Intermediate & 32.8 & 31.6 \\
\hline Urban & 36.8 & 52.7 \\
\hline \multicolumn{3}{|l|}{ Employment deprivation (quintile) } \\
\hline (least deprived) 1 & 19.9 & 8.6 \\
\hline 2 & 20.2 & 12.4 \\
\hline
\end{tabular}




\begin{tabular}{rll}
3 & 20.6 & 16.4 \\
4 & 20.4 & 21.0 \\
5 & 18.9 & 41.6 \\
\hline
\end{tabular}

559

(most deprived) 5

18.9

560 
Table 2. Association between risk of teenage motherhood and individual and household explanatory factors in

562 Northern Ireland, 2001-2005 ( $N=14,055)$. Only individual and household variables presented to the

563 multivariable models are included in the table (i.e. long term limiting illness excluded). Models are also

564 adjusted for employment-based area deprivation and rurality.

\begin{tabular}{|c|c|c|c|c|c|c|}
\hline & \multicolumn{2}{|c|}{ Unadjusted } & \multicolumn{2}{|c|}{$\begin{array}{l}\text { Fully adjusted (model } \\
\text { A) }\end{array}$} & \multicolumn{2}{|c|}{$\begin{array}{l}\text { Fully adjusted minus } \\
\text { house value (model D) }\end{array}$} \\
\hline & OR & $95 \% \mathrm{Cl}$ & OR & $95 \% \mathrm{Cl}$ & OR & $95 \% \mathrm{Cl}$ \\
\hline \multicolumn{7}{|l|}{ Individual } \\
\hline \multicolumn{7}{|l|}{ General health } \\
\hline Good & 0.69 & $(0.56,0.85)$ & 0.90 & $(0.73,1.11)$ & 0.88 & $(0.71,1.08)$ \\
\hline Fair & 1.00 & & 1.00 & & 1.00 & \\
\hline Not good & 0.72 & $(0.42,1.24)$ & 0.72 & $(0.42,1.21)$ & 0.70 & $(0.41,1.19)$ \\
\hline \multicolumn{7}{|l|}{ Religion } \\
\hline Roman Catholic & 1.00 & & 1.00 & & 1.00 & \\
\hline Church of Ireland & 1.03 & $(0.82,1.29)$ & 1.17 & $(0.94,1.46)$ & 1.26 & $(1.02,1.56)$ \\
\hline Methodist & 0.98 & $(0.65,1.49)$ & 1.23 & $(0.82,1.83)$ & 1.32 & $(0.88,1.96)$ \\
\hline No religion & 1.36 & $(1.09,1.68)$ & 1.42 & $(1.15,1.76)$ & 1.50 & $(1.22,1.86)$ \\
\hline Other Christian & 0.45 & $(0.29,0.70)$ & 0.66 & $(0.43,1.02)$ & 0.72 & $(0.47,1.11)$ \\
\hline Presbyterian & 0.77 & $(0.61,0.96)$ & 1.06 & $(0.86,1.31)$ & 1.12 & $(0.90,1.38)$ \\
\hline \multicolumn{7}{|l|}{ Living with both parents } \\
\hline Yes & 1.00 & & 1.00 & & 1.00 & \\
\hline No & 2.61 & $(2.26,3.01)$ & 1.34 & $(1.03,1.75)$ & 1.42 & $(1.09,1.84)$ \\
\hline \multicolumn{7}{|l|}{ (Head of) household } \\
\hline \multicolumn{7}{|l|}{ Economic activity } \\
\hline Unemployed & 2.65 & $(2.01,3.51)$ & 1.30 & $(0.93,1.82)$ & 1.39 & $(1.00,1.94)$ \\
\hline Inactive/Student & 2.43 & $(2.09,2.84)$ & 1.13 & $(0.94,1.37)$ & 1.22 & $(1.02,1.46)$ \\
\hline \multicolumn{7}{|l|}{ Social class (NS-SEC) } \\
\hline Professional/Managerial & 0.68 & $(0.54,0.87)$ & 0.79 & $(0.62,1.00)$ & 0.73 & $(0.57,0.92)$ \\
\hline $\begin{array}{r}\text { Intermediate/Small } \\
\text { employers/Self employed }\end{array}$ & 1.00 & & 1.00 & & 1.00 & \\
\hline Lower supervisory/routine & 1.66 & $(1.37,2.01)$ & 0.95 & $(0.78,1.16)$ & 1.04 & $(0.86,1.27)$ \\
\hline $\begin{array}{r}\text { Long term unemployed/full-time } \\
\text { student }\end{array}$ & 2.75 & $(2.14,3.54)$ & 0.98 & $(0.73,1.32)$ & 1.07 & $(0.80,1.44)$ \\
\hline \multicolumn{7}{|l|}{ Housing tenure } \\
\hline $\begin{array}{r}\text { Owner occupied: more than } \\
£ 200,000\end{array}$ & 0.13 & $(0.08,0.22)$ & 0.25 & $(0.15,0.43)$ & & \\
\hline $\begin{array}{r}\text { Owner occupied: } £ 150,000- \\
£ 199,999\end{array}$ & 0.29 & $(0.20,0.41)$ & 0.50 & $(0.34,0.72)$ & & \\
\hline $\begin{array}{r}\text { Owner occupied: } £ 100,000- \\
f 149,999\end{array}$ & 0.46 & $(0.35,0.60)$ & 0.65 & $(0.49,0.85)$ & & \\
\hline $\begin{array}{r}\text { Owner occupied: } £ 75,000- \\
£ 99,999\end{array}$ & 0.83 & $(0.63,1.08)$ & 0.91 & $(0.69,1.19)$ & & \\
\hline $\begin{array}{r}\text { Owner occupied: less than } \\
£ 75,000\end{array}$ & 1.00 & & 1.00 & & & \\
\hline Owner occupied: value unknown & 0.32 & $(0.19,0.52)$ & 0.53 & $(0.32,0.87)$ & & \\
\hline Privately rented & 1.33 & $(0.98,1.82)$ & 1.14 & $(0.82,1.57)$ & & \\
\hline Social rented & 1.66 & $(1.32,2.09)$ & 1.08 & $(0.84,1.38)$ & & \\
\hline \multicolumn{7}{|l|}{ Car access } \\
\hline None & 1.00 & & 1.00 & & 1.00 & \\
\hline One & 0.44 & $(0.37,0.51)$ & 0.76 & $(0.63,0.92)$ & 0.70 & $(0.58,0.84)$ \\
\hline Twot & 0.18 & $(0.15,0.22)$ & 0.59 & $(0.45,0.76)$ & 0.45 & $(0.35,0.58)$ \\
\hline
\end{tabular}


566 Table 3-Comparison of multivariable models of risk of teenage motherhood in Northern Ireland, 5672001 - 2005. Model fit assessed using Akaike's Information Criterion (AIC). Models in order of 568 decreasing fit. A difference in AIC of four or greater indicates a substantial difference in explanatory 569 power between two models.

\begin{tabular}{clcc}
\hline Model & Details & AIC & df \\
\hline A & Fully adjusted & 6158 & 32 \\
B & Fully adjusted minus interaction & 6162 & 30 \\
C & Fully adjusted minus car access & 6171 & 30 \\
D & Fully adjusted minus house value & 6197 & 25 \\
E & Fully adjusted minus area factors & 6203 & 24 \\
\hline
\end{tabular}


Table 4. Association between risk of teenage motherhood and area explanatory factors in Northern Ireland,

$5732001-2005(\mathrm{~N}=14,055)$. Only variables presented to the multivariable model are included in the table. Variables

574 excluded from the final multivariable model: long term limiting illness. Fully adjusted model: general health,

575 religion, living with both parents, economic activity, social class, housing tenure, car access.

\begin{tabular}{|c|c|c|c|c|c|c|}
\hline & \multicolumn{2}{|c|}{ Unadjusted model } & \multicolumn{2}{|c|}{ Fully adjusted (model A) } & \multicolumn{2}{|c|}{$\begin{array}{l}\text { Fully adjusted minus } \\
\text { car access (model C) }\end{array}$} \\
\hline & OR & $95 \% \mathrm{Cl}$ & OR & $95 \% \mathrm{Cl}$ & OR & $95 \% \mathrm{Cl}$ \\
\hline \multicolumn{7}{|l|}{ Area } \\
\hline \multicolumn{7}{|l|}{ Settlement band } \\
\hline Rural & 0.55 & $(0.44,0.69)$ & 0.81 & $(0.61,1.07)$ & 0.76 & $(0.58,1.01)$ \\
\hline Intermediate & 1.00 & & 1.00 & & 1.00 & \\
\hline Urban & 1.47 & $(1.23,1.77)$ & 1.42 & $(1.13,1.78)$ & 1.45 & $(1.16,1.82)$ \\
\hline \multicolumn{7}{|l|}{$\begin{array}{l}\text { Employment deprivation } \\
\text { (quintile) }\end{array}$} \\
\hline (least deprived) 1 & 1.00 & & 1.00 & & 1.00 & \\
\hline 2 & 1.40 & $(1.02,1.92)$ & 1.17 & $(0.86,1.59)$ & 1.15 & $(0.84,1.56)$ \\
\hline 3 & 1.94 & $(1.48,2.56)$ & 1.38 & $(1.04,1.82)$ & 1.34 & $(1.01,1.77)$ \\
\hline 4 & 2.69 & $(2.01,3.60)$ & 1.52 & $(1.13,2.05)$ & 1.47 & $(1.09,1.98)$ \\
\hline (most deprived) 5 & 4.97 & $(3.84,6.42)$ & 1.98 & $(1.49,2.63)$ & 1.88 & $(1.41,2.50)$ \\
\hline
\end{tabular}

576

577 
Table 5. Association between risk of teenage motherhood for cohort members by age and marital status of 579 members' mothers, Northern Ireland, 2001-2005. Only cohort members living with mothers were included $580(\mathrm{~N}=12,942)$. Fully adjusted model: general health, religion, economic activity, social class, housing tenure, car 581 access, settlement band, employment deprivation.

\begin{tabular}{rrrrrr}
\hline & \multicolumn{2}{c}{ Unadjusted model } & \multicolumn{2}{l}{ Fully adjusted } \\
& & & & & \\
\multicolumn{1}{l}{$\begin{array}{l}\text { Mothers age (at birth of } \\
\text { cohort member) }\end{array}$} & & & & & \\
& $<20$ & 3.79 & $(2.86,5.03)$ & 2.23 & $(1.68,2.97)$ \\
$20-29$ & 1.83 & $(1.52,2.20)$ & 1.52 & $(1.27,1.83)$ \\
$\geq 30$ & 1.00 & & 1.00 & \\
Mothers marital status & & & & \\
Single & 3.33 & $(2.33,4.76)$ & 1.15 & $(0.79,1.67)$ \\
Married & 1.00 & & 1.00 & \\
Separated & 3.26 & $(2.67,3.99)$ & 1.43 & $(1.15,1.80)$ \\
Divorced & 3.35 & $(2.70,4.17)$ & 1.63 & $(1.29,2.06)$ \\
Re-married & 2.34 & $(1.67,3.28)$ & 1.80 & $(1.29,2.53)$ \\
Widowed & 1.91 & $(1.21,3.02)$ & 1.37 & $(0.86,2.17)$ \\
\hline
\end{tabular}




\section{$583 \quad$ Figures}

584 Figure 1. Predicted probability (\%) of teenage motherhood by rurality and family structure.

585 Predictions from fully adjusted model (A) with all other variables at mean values.

586

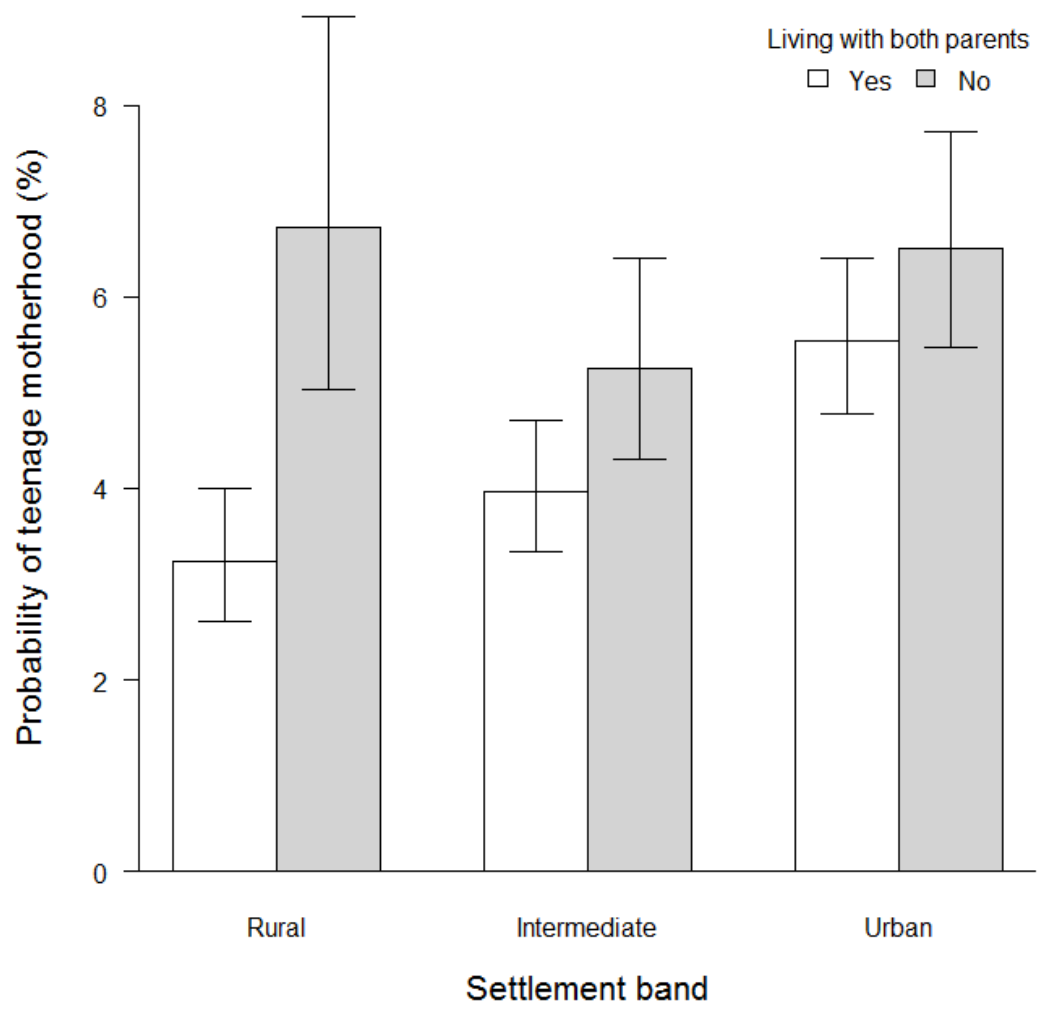

587 